\title{
The competitive attitude scale (CAS): a multidimensional measure of competitiveness in adolescence
}

\begin{abstract}
The present study aims to evaluate the structure and the construct validity of the Competitive Attitude Scale (CAS) among adolescents. This is composed by two dimensions Hypercompetitive Attitude (HCA scale by Ryckman et al..$^{1}$ ) and Personal Development Competition Attitude (PDCA scale by Ryckman et al. ${ }^{2}$ ). 1011 high school students (583 males and 428 females; age range $14-16$ years; $\mathrm{M}=14.96$; $\mathrm{DS}=.80$ ) took part at the study. Results from Exploratory and Confirmatory Factor Analysis showed the presence of two dimensions: hypercompetitive attitudes and developmental competitive attitudes which are moderately and positively associated. Following previous literature, the Competitive Attitude Scale can represent a parsimonious measure able to detect these two competitive styles during adolescence.
\end{abstract}

Keywords: adolescence, competitiveness, multidimensional, scale, construct validity
Volume 9 Issue 3 - 2018

\author{
Ersilia Menesini, Fulvio Tassi, Annalaura \\ Nocentini \\ Department of Educational Sciences and Psychology, University \\ of Florence, Italy
}

Correspondence: Ersilia Menesini, Department of Educational Sciences and Psychology, University of Florence, Via di San Salvi, 12, Complesso di San Salvi Padiglione 26, 50 I35, Florence, Italy, Email ersilia.menesini@unifi.it

Received: August 16, 2017| Published: May 02, 2018

\section{Introduction}

In western societies competition plays a relevant role in social, economic, educational and sport contexts. Despite this relevance, the way we compete and the concept of competition is not univocal. Several authors have described two main types of competitive motivations or orientations:

1. The desire to have a better performance than the other.

2. The desire to improve our own personal performance. ${ }^{3-5}$

These competitive attitudes can assume different forms, which can be defined, as "positive (or adaptive)" and "negative (or maladaptive)" based on the consequent implications at interpersonal and intrapersonal level. ${ }^{4,6}$ Despite the theoretical and applied relevance of this topic, very few efforts have been made to develop measures trying to operationalize this distinction. ${ }^{3}$ To this regards, useful references are the scales of Hypercompetitive Attitude (HCA) ${ }^{1}$ and of Personal Development Competition Attitude (PDCA). ${ }^{2}$ HCA Scale refers to a strong need by individuals to compete and win (and to avoid losses) as a means to maintain or to enhance feelings of self-esteem and self-worth, with a personal orientation to manipulation, aggression, exploitation and denigration of others. The objective of HCA is not just to do well but also to demonstrate superiority at cost to opponents. PDCA Scale refers to an attitude in which the primary focus is not the outcome (i.e., on winning), but rather the enjoyment and mastery of the task. Individuals with PDCA are concerned more about selfdiscovery, self-improvement, and task-mastery than with comparison with others. Other people are not seen as competitors that hinder the winner, but rather as possible helpers who provide the individual with opportunities of personal discovery and learning. Several studies focused on the construct validity of the two scales. HCA is associated with narcissism, with low self-esteem and with failure anxiety. ${ }^{7,8}$ In relation to social attitudes HCA is associated with anger and hostility toward others, ${ }^{9}$ with dogmatism and authoritarianism. ${ }^{10}$ These results are in line with the fact that people with high levels of hypercompetitive attitudes are usually more violent with intimate partners, with other family members and with best friends. ${ }^{1}$ Adolescents with higher hypercompetitive attitudes show also higher level of bullying. ${ }^{11}$ These hypercompetitive individuals show a high level of power and control over others to the extent that this can cause psychological suffering for the victims. On the contrary, PDCA Scale is associated with higher self-esteem and to a need for affiliation. ${ }^{2}$ The PDCA, differently from HCA, is associated with social concern, care of the well-being of others and to treating them with respect. ${ }^{12}$ Furthermore PDCA is associated with forgiveness. ${ }^{13}$ Overall, HCA and PDCA are able to describe different aspects within the construct of competitiveness as compared to other measures of competitive attitudes. ${ }^{3}$ Although these two scales were developed as independent and not correlated constructs, ${ }^{1,2}$ literature reported that the two competitive attitudes are positively correlated in clinical and community samples and across different ages. ${ }^{3,13-17}$ The positive association may reflect a common underlying construct which can be regarded as bidimensional and composed by a motivation to compete with others. ${ }^{13}$ Burckle et al., ${ }^{14}$ called this as "Generalized competitive attitude". Furthermore, the two scales were originally designed for college-age sample; our study is focused on adolescents. Competitive attitudes in adolescents can be related to their needs of self development, self- assertion and of belonging to a group. Often during this stage we observe a difficult dynamics between self-assertion and acceptance in the group., ${ }^{4,18}$ Specifically we can assume that the two competitive attitudes are more correlated in this stage since they respond to different and parallel psychological needs: HCA can be relevant to define personal goals and self assertion of adolescents ; PDCA can be relevant to establish close friendships and romantic relationships. ${ }^{5}$ Starting from these considerations, the present study aims to evaluate the underlying structure and the construct validity of the Competitive Attitude Scale (CAS), composed by the two scales, HCA and PDCA, in a sample of adolescents. We hypothesize:

\section{To confirm the two dimensions}


2. That the two subscales are positively correlated, although they differ in terms of adaptive and maladaptive correlates.

\section{Method}

\section{Participants and procedure}

This sample was composed of 1011 high school students (583 males and 428 females), enrolled in grades 9,10 and 11 . Ages ranged from 14 to 16 years $(\mathrm{M}=14.96 ; \mathrm{DS}=.80)$. All the participants received permission from their parents to take part in the study. The majority of students was from an Italian background $(96 \%)$ and lived in twoparent families (91\%). Participants in this study were drawn from the first data collection of an ongoing longitudinal study started in 2002 aimed to evaluate different dimensions of the psycho-social adjustment in high school students in Lucca, a city of Tuscany- Italy (LU. LO.S.A.). The sample was representative of the school distribution in our country: $36.6 \%$ attended lyceum high school, $43.5 \%$ technical institutes and $19.8 \%$ vocational schools. The schools were selected using a self-selection inclusion in the study. Consent procedure for research consisted of school approval and parental consent. Trained assistants administered questionnaires in class during school time in two different sessions, each lasting about one hour. Participants were assured of confidentiality.

\section{Measures}

Competition: The Competitive Attitude Scale (CAS) is composed by the two subscales: the Hypercompetitive Attitude (HCA: from item 1 to item 26) ${ }^{1}$ and Personal Development Competition Attitude (PDCA: from item 27 to item 41$)^{2}$ (Table 1). The students rated each item on a 5-point Likert scale (from "Never true for me" to "Always true for me"). As indicators of maladaptive and adaptive behaviors we used bullying and prosocial behavior.

Bullying: Bullying was measured with the global item from the Olweus ${ }^{19}$ in which students were provided with a definition of bullying and asked to report the frequency of bullying others in the last two months along a 5-point scale (not at all, once or twice, 3-6 times, about once a week, several times a week).

Table I Descriptive data (means, sd, skewness, kurtosis), exploratory factor analysis (factor loadings), confirmatory factor analysis (factor loadings and intercepts)

\begin{tabular}{|c|c|c|c|c|c|c|c|}
\hline & & & EFA & & CFA & & \\
\hline & Means & sd & $\mathbf{F I}$ & $\mathbf{F 2}$ & $\mathbf{F I}$ & $\mathbf{F 2}$ & Intercept \\
\hline I.Winning in competition makes me feel more powerful as a person. & 3.23 & 1.26 & 0.59 & 0.38 & 0.57 & & 2.56 \\
\hline 2.I find myself being competitive even in situations which do not call for competition. & 2.16 & 1.14 & 0.67 & 0.34 & 0.62 & & 1.89 \\
\hline (R)3. I do not see my opponents in competition as my enemies. & 3.13 & 1.49 & & & & & \\
\hline 4. I compete with others even if they are not competing with me. & 1.92 & 1.14 & 0.62 & 0.19 & 0.54 & & 1.68 \\
\hline (R)5. Success in athletic competition does not make me feel superior to others. & 2.73 & 1.39 & & & & & \\
\hline (R)6. Winning in competition does not give me a greater sense of worth. & 2.84 & 1.39 & & & & & \\
\hline 7.When my competitors receive rewards for their accomplishments, I feel envy. & 2.29 & 1.13 & 0.58 & 0.15 & 0.49 & & 2.03 \\
\hline 8. I find myself turning a friendly game or activity into a serious contest or conflict. & 2.06 & 1.15 & 0.7 & 0.24 & 0.67 & & 1.79 \\
\hline $\begin{array}{l}\text { 9. It's a dog-eat-dog world. If you don't get the better of others, they will surely get } \\
\text { the better of you. }\end{array}$ & 2.49 & 1.29 & 0.54 & 0.15 & 0.49 & & 1.92 \\
\hline $\begin{array}{l}\text { (R) I } 0 . \text { I do not mind giving credit to someone for doing something that I could have } \\
\text { done just as well or better. }\end{array}$ & 3.65 & 1.18 & & & & & \\
\hline $\begin{array}{l}\text { I I. If I can disturb my opponent in some way in order to get the edge in competition, } \\
\text { I will do so. }\end{array}$ & 1.99 & 1.24 & 0.56 & 0 & 0.5 & & 1.6 \\
\hline I2. I really feel down when I lose in athletic competition. & 2.56 & 1.28 & 0.55 & 0.31 & 0.54 & & 1.99 \\
\hline $\begin{array}{l}\text { (R) I3. Gaining praise from others is not an important reason why I enter competitive } \\
\text { situations. }\end{array}$ & 2.97 & 1.42 & & & & & \\
\hline $\begin{array}{l}\text { I4. I like the challenge of getting someone to like me who is already going with } \\
\text { someone else. }\end{array}$ & 2.46 & 1.35 & 0.47 & 0.11 & 0.43 & & 1.81 \\
\hline (R) I5. I do not view my relationships in competitive terms. & 2.99 & 1.5 & & & & & \\
\hline $\begin{array}{l}\text { (R) I6. It does not bother me to be passed by someone while I am driving on the } \\
\text { roads. }\end{array}$ & 2.84 & 1.61 & & & & & \\
\hline I7. I can't stand to lose an argument. & 2.99 & 1.33 & 0.35 & 0.15 & & & \\
\hline $\begin{array}{l}\text { (R) I 8. In school, I do not feel superior whenever I do better on tests than other } \\
\text { students. }\end{array}$ & 3.18 & 1.54 & & & & & \\
\hline $\begin{array}{l}\text { (R) I } 9.1 \text { feel no need to get even with a person who criticizes or makes me look bad } \\
\text { in front of others. }\end{array}$ & 2.72 & 1.33 & & & & & \\
\hline (R)20. Losing in competition has little effect on me. & 2.89 & 1.3 & & & & & \\
\hline
\end{tabular}


Table Continued

\begin{tabular}{|c|c|c|c|c|c|c|c|}
\hline & & & EFA & & CFA & & \\
\hline & Means & sd & FI & $\mathbf{F 2}$ & FI & $\mathbf{F 2}$ & Intercept \\
\hline 2I. Failure or loss in competition makes me feel less worthy as a person. & 1.85 & 1.14 & 0.51 & 0.1 & 0.45 & & 1.63 \\
\hline 22. People who quit during competition are weak. & 2.28 & 1.31 & 0.6 & 0.29 & 0.57 & & 1.74 \\
\hline 23. Competition inspires me to excel. & 2.82 & 1.34 & 0.67 & 0.44 & & & \\
\hline (R)24. I do not try to win arguments with members of my family. & 2.69 & 1.3 & 0 & -0.11 & & & \\
\hline $\begin{array}{l}\text { (R) } 25 . \text { I believe that you can be a nice guy and still win or be successful in } \\
\text { competition. }\end{array}$ & 3.66 & 1.2 & & & & & \\
\hline $\begin{array}{l}\text { (R)26. I do not find it difficult to be fully satisfied with my performance in a } \\
\text { competitive }\end{array}$ & 3.3 & 1.06 & -0.18 & -0.39 & & & \\
\hline 27. I enjoy competition because it gives me a chance to discover my abilities & 3.59 & 1.25 & 0.34 & 0.74 & & 0.69 & 2.88 \\
\hline $\begin{array}{l}\text { (R)28. Competition does not increase my awareness and understanding of myself and } \\
\text { others }\end{array}$ & 2.69 & 1.28 & & & & & \\
\hline 29. Competition can lead to the formation of friendship with others & 3.48 & 1.13 & 0.11 & 0.51 & & 0.44 & 3.08 \\
\hline (R)30.Competition is not a means of motivating me to bring out the best in myself & 2.21 & 1.27 & 12 & 0.34 & & & \\
\hline $\begin{array}{l}31 . I \text { enjoy competition because it tends to bring out the best in me rather than as a } \\
\text { means of feeling better than others }\end{array}$ & 3.53 & 1.35 & 0.06 & 0.63 & & 0.57 & 2.61 \\
\hline $\begin{array}{l}\text { (R)32.I do not find competition to be a very valuable means of learning about myself } \\
\text { and others }\end{array}$ & 2.58 & 1.28 & & & & & \\
\hline 33.I like competition because it teaches me a lot about the self & 3.2 & 1.26 & 0.28 & 0.71 & & 0.69 & 2.52 \\
\hline 34.I value competition because it helps me to be the best that I can be & 3.25 & 1.26 & 0.38 & 0.76 & & 0.76 & 2.57 \\
\hline $\begin{array}{l}35 . I \text { find competition enjoyable because it lets me express my own potentials and } \\
\text { abilities during competition }\end{array}$ & 3.43 & 1.28 & 0.35 & 0.79 & & 0.79 & 2.67 \\
\hline (R)36.Competition does not help me develop my abilities more & 2.3 & 1.17 & & & & & \\
\hline $\begin{array}{l}\text { 37. Without the challenge of competition I might never discover that I had certain } \\
\text { potentials or abilities }\end{array}$ & 2.8 & 1.32 & 0.42 & 0.62 & & & \\
\hline $\begin{array}{l}38.1 \text { enjoy competition because it brings me and my competitors closer together as } \\
\text { human beings }\end{array}$ & 2.76 & 1.24 & 0.14 & 0.58 & & 0.51 & 2.22 \\
\hline $\begin{array}{l}\text { 39.I enjoy competition because it helps me to develop my own potentials more fully } \\
\text { than if I engaged in these activities alone }\end{array}$ & 3.22 & 1.28 & 0.35 & 0.72 & & 0.7 & 2.51 \\
\hline $\begin{array}{l}40.1 \text { enjoy competition because it brings me to a higher level of motivation to bring } \\
\text { the best out of myself rather than as a means of doing better than others }\end{array}$ & 3.45 & 1.26 & 0.13 & 0.7 & & 0.63 & 2.74 \\
\hline 4I.Through competition I feel that I am contributing to the well-being of others & 2.28 & 1.15 & 0.19 & 0.44 & & 0.4 & 1.97 \\
\hline
\end{tabular}

Notes: In the CFA all the factor loadings and the intercepts are significant at level $p<.00$ I. Final items are in bold.

Prosocial behaviors: A prosocial behavior scale was derived by the Youth Self Report. ${ }^{20}$ In particular 3 items, rated on 3-point scale, were considered with a reliability coefficient of .76: I like to help others, I try to help others when I can; I am likely to help others when they need.

\section{Data analysis}

In order to evaluate the dimensional structure of the scale we initially used exploratory factor analysis $(E F A)$, and then, to further investigate the structure of the scale, we performed maximum likelihood Confirmatory Factor Analysis (CFA). Finally, to evaluate the construct validity we used partial correlation analyses with two different behaviors: bullying and prosocial behavior. All the analyses were made using SPSS/PASW version 18.0 and Mplus 5.0. ${ }^{21}$

\section{Results}

\section{Exploratory Factor Analysis (EFA)/reliability}

Descriptive data of the scale are presented on Table 1. The 41 items were subjected to a preliminary principal axis factoring analysis with an Oblimin rotation. Initially, a three-factor solution was found with $39.3 \%$ of cumulative percentages of variance explained. The first and the second factor corresponded to the Hyper-Competitive Attitude (HCA) and to the Developmental-Competitive Attitude (DCA) constructs respectively. However, the third factor was composed by fourteen reversed items from both scales (items: 3-5-6-10-13-1516-18-19-20-25-28-32-36): given that no theoretical meaning was characteristic of this factor, we assumed that these items were difficult to understand because of their negative nature. Thus, we deleted them and we re-tested the EFA. A two-factors solution was found with 
$36.12 \%$ cumulative percentages of variance explained. Items 17, 24 and 26 were deleted from Factor 1 and item 30 was deleted from Factor 2 because their factor loadings were lower than .40 . Furthermore, item 23 and 37 were deleted because of their cross-loading (crossloading was defined when both factor loadings were higher than .40). The two final factors were: Hyper-Competitiveness (HC), composed by 11 items: 1-2-4-7-8-9-11-12-14-21-22 and DevelopmentalCompetitiveness (DC), composed by 10 items: 27-29-31-33-34-3538-39-40-41. The two factors resulted positively correlated $(\mathrm{r}=.34)$. Reliability coefficients were .81 and .87 respectively.

\section{Confirmatory Factor Analyses (CFA)}

CFA using the sample covariance matrices was calculated to confirm the factor structure previously found by EFA. The model presented an acceptable fit: $\chi^{2}(186)=880.761, C F I=.90, R M S E A=.058$ (.054-.061), SRMR=.055. As we can see from Table 1 all the factor loadings are significant and higher than .40 and all the intercepts are significant. Factor correlation is .28

\section{Construct Validity}

Given the correlation between the two factors, we performed a partial correlation analysis to evaluate the association between the two factors and the two concurrent behaviors, bullying and prosocial behavior. Controlling for PDCA, HCA is positively correlated with bullying $(\mathrm{r}=.24 * * *)$ and negatively correlated with prosociality $(\mathrm{r}=-$ $.20^{* * *}$ ). Controlling for HCA, PDCA is not correlated with bullying $(\mathrm{r}=.01)$ but it is positively correlated with prosociality $\left(\mathrm{r}=.13^{* * *}\right)$

\section{Discussion}

The study confirms the utility of a multidimensional conceptualization of the competitive attitude construct and its relevance to measure competitive styles in adolescence. In relation to the first issue, results underlined that the construct of competition can be regarded as bidimensional, i.e. consisting of hypercompetitive attitude and developmental competitive attitude which are likely to be moderately and positively associated. These data support a previous study where the two dimensions are two components of a Generalized Competitiveness Scale,$^{14}$ and they are consistent with several studies where the two dimensions were found to be positively associated..$^{2,3,13-17}$ Although these constructs were originally presented as independent, the positive association may reflect a strong desire to win in competition, where the primary motivation for winning differs between these two competitive orientations. ${ }^{13}$ In line with this view, hypercompetitiveness and personal development competitiveness share values related to self-contained individualism (i.e. achievement, hedonism, stimulation) but they differ because the former is related to the value of power and control over the opponents and the latter is related to the value of social concern. ${ }^{12}$ This motivational distinction is relevant for adolescents and it is evident in terms of quality of social relationships. In fact, hypercompetitive attitude was positively correlated with bullying and negatively with prosociality, whereas personal developmental competitive style is positively associated with prosocial behavior and not with bullying. In relation to the second issue, the present study confirms the relevance of a multidimensional construct for adolescents, able to define and measure different competitive styles during this stage. Although individual competitiveness may facilitate the establishment of educational and career identity, when this competition involves a comparison with others based on the control and on the need to be successful at all costs, it may interfere with positive relationships and elicit more negative and dominant behaviors such as bullying. This, in turn, can have a detrimental impact on the individual's development and on personality functioning

Overall, results of the present study confirm the relevance of a single construct of competition that ranges from a motivation to win over the others to a motivation to personal development and improvement in the task. . The Competitive Attitude Scale (CAS), composed by two different dimensions which can co-occur and are associated with different adaptive and maladaptive behaviors, can be a tool able to detect these two characteristics during adolescence.

\section{Acknowledgment}

None.

\section{Conflict of interest}

The author declares that there is no conflict of interest.

\section{References}

1. Ryckman RM, Hammer M, Kaczor LM, et al. Construction of a hypercompetitive attitude scale. Journal of Personality Assessment. 1990;55(3-4):630-639.

2. Ryckman RM, Hammer M, Kaczor LM, et al. Construction of a personal development competitive attitude scale. Journal of Personality Assessment. 1996;66(2):374-385.

3. Houston JM, Mcintire SA, Kinnie J, et al. A Factorial Analysis of Scales Measuring Competitiveness. Educational and Psychological Measurement. 2002;62:284-298.

4. Schneider BH. Childhood Friendships and Peer Relations: Friends and Enemies. New York: Routledge; 2016.

5. Hibbard DR, Buhrmester D. Competitiveness, Gender, and Adjustment Among Adolescents. Sex Roles. 2010;63(5-6):412-424.

6. Richard JF, Fonzi A, Tani F, et al. Cooperation and competition. In: Smith PK, editor. Blackwell Handbook of Child Social Development. Blackwell; 2002:515-532.

7. Luchner AF, Houston JM, Walker C, et al. Exploring the relationship between two forms of narcissism and competitiveness. Personality and Individual Differences. 2011;51:779-782.

8. Ryckman RM, Thornton B, Butler JC. Personality correlates of the hypercompetitive attitude scale. Journal of Personality Assessment. 1994;66:374-385.

9. Ross SR., Rausch MK, Canada KE. Competition and cooperation in the five-factor model: individual differences in achievement orientation. Journal of Psychology. 2003;137(4):323-337.

10. Dru V. Relationships between an ego orientation scale and a hypercompetitive scale: Their correlates with dogmatism and authoritarianism factors. Personality and Individual Differences. 2003;35(7):1509-1524.

11. Nocentini A, Menesini E, Salmivalli C. Level and change of bullying behavior during high school: A multilevel growth curve analysis. Journal of Adolescence. 2013;36(3):495-505.

12. Ryckman RM, Libby CR, van den Borne B, et al. Values of hypercompetitiveness and personal development competitive individuals. Journal of Personality Assessment. 1997;69(2):271-283. 
13. Collier SA, Ryckman RM, Thornton B, et al. Competitive personality attitudes and forgiveness of others. Journal of Psychology. 2010;144(6):535-543.

14. Burckle MA, Ryckman RM, Gold JA, et al. Forms of competitive attitude and achievement orientation in relation to disordered eating. Sex Roles. 1999;40(11-12):853-870.

15. Houston JM, Edge H, Aoderson LE, et al. Competitiveness and Individualism-Collectivism in Bali and the U.S. North American, Journal of Psychology. 2012;14(1):163-173.

16. Koltai M, Bognár J, Fügedi B. Examining the Efficiency of Collective Task-Solving among Hungarian Volleyball Players. International Quarterly of Sport Science. 2009;4:21-27.
17. Ryska TA. Perceived purposes of sport among recreational participants: the role of competitive dispositions. Journal of Sport Behavior. 2002;25:91-112.

18. Erikson EK. Identity: Youth and Crisis. New York: W.W. Norton. 1968.

19. Olweus D. Bullying at school: What we know and what we can do. Cambridge, MA: Blackwell Publishers, Inc; 1993.

20. Achenbach TM, Edelbrock C. Manual for the Youth Self Report and Profile. Burlington, Vt: University of Vermont, Department of Psychiatry. 1991.

21. Muthén LK, Muthén BO. MPlus user's guide version 5.1. Los Angeles, CA: Muthén \& Muthén. 2007. 